\title{
Considerações acerca da indignação social: os limites da tolerância ao sofrimento alheio
}

\section{Consideration on Social Indignation: The Limits of Tolerance to the Suffering of Others}

\section{Consideración sobre la indignación Social: Los Límites de la Tolerancia al Sufrimiento de Otros}

\author{
Sandra Leal de Melo Dahia* \\ Universidade Federal da Paraíba - UFPB, João Pessoa, Paraíba, Brasil
}

\begin{abstract}
RESUMO
Este artigo aborda a questão da indignação social com o sofrimento alheio a partir de uma perspectiva psicossocial. Inspirados em um estudo anterior que sugere que uma alta intensidade de agressividade em atos discriminatórios é capaz de provocar indignação, desenvolvemos algumas reflexões que aproximam aspectos dos trabalhos teóricos do psicanalista Christoph Dejours e do sociólogo Norbert Elias. O pensamento de Dejours permite entender como, no nível psíquico, reações adaptativas de tolerância ao sofrimento podem ser construídas progressivamente como estratégia para apagar a responsabilidade social na sua produção. Ele demonstra, através de uma análise realizada no mundo do trabalho, como a adesão a determinadas representações sociais contribui para tais mecanismos de defesa contra o sofrimento dos outros na sociedade atual. Tal processo, segundo Dejours, conduz a uma espécie de domesticação da reação de indignação social. Partindo de um ponto de vista histórico, Elias defende a ideia de um controle progressivo das emoções. Ele evidencia a moldagem histórica de estruturas sociais e psíquicas na formação de configurações sociais que informam modelos de interações, cujas expressões apresentam, a cada tempo, um padrão emocional específico. Consideramos, neste estudo, a possibilidade de que certas configurações emocionais atuais, tal como a atenuação da reação de indignação, possa ser reconhecida como um novo padrão emocional, principalmente ante formas não ostensivas de sofrimento, integrando um dos caminhos possíveis do processo civilizador.

Palavras-chave: indignação, estruturas, sofrimento.
\end{abstract}

\section{ABSTRACT}

This article approaches the social indignation issue with others suffering based on psychosocial perspective. Inspired by previous study that suggests that high aggressiveness intensity in discrimination acts can provoke indignation, we developed reflections that bring close theoretical works aspects of psychoanalyst Christoph Dejours and sociologist Norbert Elias. Dejours' thought allows understanding how, in psychic level, adaptive tolerance reactions to suffering can progressively built strategy to switch off social responsibility in its production. It shows, through analysis performed 
in working world, and adhesion to certain social representations contributes to defence mechanisms suffering of others in society today. Such process, according to Dejours, leads to a kind of reaction domestication of social indignation. Starting from a historical point of view, Elias defends the idea of progressive control of emotions. It highlights historical moulding of social and psychic structures on formation of social configuration that informs interaction models, which expressions present, at times, specific emotional pattern. We consider, in this study, the possibility that certain emotional configurations today, with attenuation of indignation reaction, can be recognized as a new emotional pattern, especially against non-ostensive suffering forms. Being able to integrate one of the possible ways of the process civilized.

Keywords: indignation, structures, suffering.

\section{RESUMEN}

Este artículo aborda el tema de indignación social con otros que sufren desde la perspectiva psicosocial. Inspirado en estudio previo que sugiere que la intensidad de agresividad en actos de discriminación puede provocar indignación, desarrollamos reflexiones acercan aspectos teóricos del psicoanalista Christoph Dejours y sociólogo Norbert Elias. El pensamiento de Dejours permite comprender, en nivel psíquico, reacciones de tolerancia adaptativa al sufrimiento pueden construir progresivamente estrategia para apagar responsabilidad social en su producción. Se muestra, a través del análisis realizado en mundo del trabajo, y adhesión a ciertas representaciones sociales contribuye mecanismos de defensa del sufrimiento de los demás en sociedad actual. Tal proceso, según Dejours, conduce una especie de reacción domesticación de indignación social. Partiendo de punto de vista histórico, Elías defiende la idea del control progresivo de emociones. Se destaca moldeo histórico de estructuras sociales y psíquicas sobre formación de configuración social informando modelos de interacción, que expresiones presentan, a veces, patrón emocional específico. Consideramos, este estudio, la posibilidad de ciertas configuraciones emocionales actuales, con atenuación de reacción de indignación, puedan reconocer nuevo patrón emocional, especialmente contra formas de sufrimiento no ostensivas. Ser capaz de integrar posibles vías del proceso civilizado.

Palabras clave: indignación, estructuras, sufrimiento.

\section{I ntrodução}

O sofrimento alheio nos provoca indignação social, nos dias de hoje? Quando ele se torna intolerável? O sofrimento dos outros é uma evidência ou os outros precisam dar visibilidade ao seu sofrimento? É a sinalização dos que sofrem que cria a evidência? É necessário, portanto, que o outro manifeste seu descontentamento para que a situação seja interpretada como indigna e suscite uma reação, ou o sofrimento alheio é identificado e evidenciado por outros fatores?

As questões acima foram elaboradas a partir dos resultados de uma pesquisa anterior sobre preconceito racial que, embora não sendo objeto da presente análise, serviram de inspiração para o desenvolvimento de nossas reflexões acerca do pungente tema da indignação social e dos limites da tolerância ao sofrimento do outro. 
Os resultados da referida pesquisa sugerem que o limite desencadeador para reações de indignação social com o sofrimento alheio parece estar relacionado à percepção de forte agressividade em discursos e atos discriminatórios. Outros estudos (Vala, 1999) indicam uma tendência nas manifestações do preconceito que apontam para expressões cada vez mais "civilizadas" e sutis, hoje, no mundo ocidental. Estas são perspectivas que conferem certa razoabilidade a suposição de que a expressão intensa de agressividade e violência aberta são fatores que podem se tornar decisivos para a identificação do sofrimento alheio, demarcando a fronteira entre o que se pode e o que não se pode tolerar. De um modo geral, a indignação pode ser compreendida como um sentimento de revolta ante um acontecimento considerado ofensivo ou injusto que pode levar a estratégias defensivas, no nível psíquico e social, ou a intervenções em favor da vítima. Embora, inúmeros elementos possam interferir neste complexo contexto, consideramos que a percepção do grau de agressividade envolvido na experiência pode se tornar um fator importante na decisão de intervir e, de forma indireta, pode contribuir para estabelecer certa regulação social na expressão das manifestações emocionais.

Nossa discussão seguirá dois eixos de análises principais que buscam fundamentação na articulação de aspectos teóricos dos pensamentos de Cristophe Dejours e Norbert Elias. O primeiro eixo se relaciona à forma como as subjetividades constroem formas adaptativas para tolerar progressivamente o sofrimento alheio e à importância conferida à mediação das representações sociais na apreensão da realidade para compreender os vieses interpretativos, sob os quais o sofrimento do outro pode ser percebido ou pode ser invisibilizado. Como aporte teórico para tratar das referidas questões, propomos o viés analítico do psicanalista Cristophe Dejours. O segundo eixo se volta para a consideração da influência dos elementos históricos e culturais na construção de padrões de expressão emocional que, relacionando estruturas psíquicas e sociais, instituem, a cada tempo, os limites do que é possível tolerar. Recorreremos ao sociólogo Norbert Elias para tentar delinear como o entendimento sobre 0 sofrimento e seus limites têm sido sucessivamente reinventados, e como certos padrões históricos de expressão emocional, a exemplo da agressividade excessiva, Ihe concedem maior visibilidade, podendo levar a um estado de indignação social e, quando destituídos de expressão emocional intensa, à indiferença social.

\section{A (não) evidência do sofrimento alheio}

De acordo com o psicólogo social Serge Moscovici “as representações sociais são fenômenos específicos que estão relacionados com 0 
modo particular de compreender e de se comunicar, um modo que cria tanto a realidade como o senso comum" (2003, p.49). A pertinência do fenômeno da representação social é demonstrada de um modo geral e, particularmente, para o presente estudo, através de alguns fatos significativos. Um deles é a ideia da não determinação da realidade do mundo objetivo sobre nossos sistemas cognitivos, tendo em vista que, as vezes, não percebemos o que está de forma material diante dos nossos olhos. A visibilidade das coisas e pessoas ou as reações a elas parecem ser afetadas por certas compreensões que têm o poder de estabelecer uma fragmentação da realidade, eclipsando nossa visão e tornando invisíveis aspectos da realidade que estão diante de nós ou conferindo materialidade a meras ilusões sedimentadas por uma imagem ou ideia construídas coletivamente. Em suma, as representações sociais influenciam o que vemos e o modo como vemos. É, nesse sentido, que a questão sobre a visibilidade do sofrimento do outro ganha pertinência, uma vez que ele pode não ser uma evidência.

Outro aspecto fundamental, que confere importância às representações, é o fato de sermos influenciados por esses filtros perceptivos, com base em definições compartilhadas por integrantes de nossas comunidades. Em certas circunstâncias, as pessoas parecem indiferentes à sorte dos outros porque, de fato, não percebem sua adversidade. Moscovici (2003) defende a ideia do domínio de algumas representações sociais na estrutura do pensamento de certas sociedades que produzem concepções de mundo específicas, dando, portanto, evidência a determinados fatos e invisibilizando outros. Nos dias de hoje, por exemplo, o individualismo é uma representação social dominante no mundo ocidental. Como valor central do sistema capitalista neoliberal, o individualismo professa a ideia de que cada indivíduo é um ser moral dotado de direitos fundamentais como liberdade e igualdade. Um dos fundamentos destes direitos encontra-se na noção de natureza humana, o que implica considerar que para desenvolver seu potencial natural, este indivíduo depende principalmente de seu próprio esforço, dispensando a influência de vínculos sociais e políticos (Bock, 1999). Ele se torna, enfim, o artífice dos seus sucessos, dos seus fracassos e de suas adversidades. A interpretação dos valores individualistas é, no entanto, multifacetada e pode servir a diferentes interesses. Assim, se muitas vezes, a causa do sofrimento pode ser atribuída à própria vítima da injustiça, isentando seus espectadores de responsabilidade e de uma reação de solidariedade, em outras, a condição de vulnerabilidade de grupos ou indivíduos ao sofrimento pode ficar obscurecida pelo imperativo de não interferir em assuntos privados. A ameaça de contrariar a liberdade de quem provoca a situação de injustiça e interferir na livre iniciativa de reação de quem a sofre, em alguns casos, parece ferir mortalmente os princípios 
individualistas e isso inibe, significativamente, qualquer reação em favor da vítima ---, em um alusivo sinal de reconhecimento de seu direito individual de manifestação. Dentro dessa lógica, também é possível identificar elementos desencadeadores que se relacionam com a prerrogativa de liberdade dos indivíduos que sofrem. Por exemplo, em certos casos, o sofrimento alheio parece ser identificado pela sinalização da própria vítima. Esta compreensão reforça os resultados apontados em um artigo de Dominic Packer (2008) sobre o clássico experimento realizado por Stanley Milgram nos anos 60. Milgram (1974) realizou um engenhoso experimento que tentava verificar o grau de submissão de sujeitos experimentais à autoridade, impelindo-os a aplicar falsos choques elétricos progressivos, que variavam de 15 a 450 volts, em outros indivíduos.

Como conclusão, foi demonstrado um alto índice de submissão à autoridade. Numa meta-análise dos resultados de oito dos quase vinte experimentos realizados por Milgram, Packer (2008) verificou que a desobediência dos sujeitos experimentais era mais provável na aplicação dos 150 volts, exatamente quando a suposta vítima pedia que interrompessem 0 experimento. Esta desobediência não foi igualmente relacionada a crescentes expressões de dor. O padrão de desobediência dos participantes pareceu apontar, segundo Packer, um momento crítico, no qual se reconheceu o direito da vítima de encerrar o experimento.

O pedido de ajuda da vítima pode expressar, em certas circunstâncias, a "autorização" requerida para uma intervenção. A história tem mostrado que os movimentos coletivos legítimos que a atravessam, embora usualmente esvaziados de crédito por um viés ideológico, sempre vicejaram a partir da iniciativa dos próprios grupos vitimados por alguma opressão. A experiência e o sentimento de opressão podem fortalecer interesses comuns e, a partir de uma ação coletiva bem organizada, fornecer tangibilidade a certas necessidades "ocultas" à sociedade.

Além destas, outras representações circulantes no nosso meio, que alimentam a vitalidade do sistema neoliberal, podem desvincular a adversidade da ideia de responsabilidade e, dessa forma, atribuir sua causa a fatores abstratos e incontroláveis designados como fenômeno sistêmico, fenômeno econômico, fatalidade ou destino. Estes vieses perceptivos, comprometidos com mecanismos individuais e coletivos de transferências de responsabilidades acerca da origem do sofrimento, estão tão entranhados em nós que, muitas vezes, servem de autojustificativa para a tolerância e, diríamos mesmo, para a cumplicidade com o sofrimento dos outros. Esta é a tese defendida pelo psiquiatra e psicanalista Christoph Dejours, em sua obra, "A Banalização da Injustiça Social" (2006). A partir de um referencial psicanalítico e psicodinâmico, Dejours reflete sobre a injustiça social e o sofrimento psíquico que se produz, especificamente, no mundo do 
trabalho e discute as estratégias defensivas sob as quais o sofrimento é tolerado por suas vítimas e por seus espectadores. Em um sistema capitalista neoliberal, no universo das relações de trabalho, sempre estão envolvidas relações de desigualdades nas quais os desfavorecidos são confrontados com situações de injustiça. Dejours nos adverte que a adesão ao discurso que dissocia a adversidade da injustiça na explicação do desemprego e da exclusão social é um efeito do processo de banalização do mal, que ele compreende como um processo complexo de atenuação da consciência moral ante o sofrimento do outro e de tolerância crescente à injustiça. Neste discurso subjaz uma distinção entre a noção de sofrimento, encarado como fatalidade, e do sofrimento causado por uma situação de injustiça. O sofrimento advindo de uma fatalidade não subtende nenhum responsável, nenhuma causa definida. Embora gere compaixão, não é capaz de suscitar sentimento de indignação. Muito ao contrário, seu efeito mais provável é um inativo estado de resignação e desmobilização política. Não obstante, quando o sofrimento é atrelado a uma situação de injustiça, o tema da responsabilidade emerge e se sobrepõe. O exercício de atribuição de responsabilidade torna-se imperativo, mudando todo o cenário interpretativo e, sobretudo, impelindo a uma reação política.

Em grande medida, as reações são afetadas por discursos que supõem um jogo dinâmico de juízos de atribuições de causalidades, tendo em vista que, para Dejours, a mobilização contra a injustiça, própria ou do outro, se relaciona muito mais intimamente ao sentimento de cólera ou indignação contra o sofrimento percebido como intolerável do que pela busca de felicidade. Ele sugere que se trata muito mais de uma questão de reação do que de ação propriamente dita. Mas, se não houver reconhecimento de uma situação de injustiça tampouco haverá mobilização e protesto. Para denotar esta condição de suposta indiferença das pessoas à situação de sofrimento alheio, Dejours recorre à noção de clivagem. Com efeito, ele descreve este mecanismo como estratégia de defesa criada pelos indivíduos "contra a consciência da própria colaboração e da própria responsabilidade no agravamento da adversidade social" (2006, p.21). A clivagem, na qual ocorre a suspensão da faculdade de submeter as coisas a juízo, em que o senso moral é sumariamente abolido, somente afeta zonas da personalidade diretamente relacionadas com a percepção do sofrimento alheio. Nesta zona nebulosa do ego, o pensamento recua e cede lugar a adesão aos discursos dominantes, eivados de lugares-comuns e de estereótipos. É a referida "banalização do mal", variante do conceito de "banalidade do mal", formulado por Hanna Arendt para compreender a escalada de violência racionalizada na Alemanha nazista rumo ao Holocausto. Tendo como referência a mobilização do povo alemão para o nazismo em um sistema totalitário, o autor investiga como 
ocorre o mesmo processo de mobilização de massa para a produção e manutenção da injustiça na sociedade contemporânea, mais precisamente na França. No caso do nazismo, o processo de racionalização da organização da ação, que distancia os agentes do sofrimento de suas vítimas, dividindo a responsabilidade social de modo tão eficiente ao ponto de diluí-la, é apontado como facilitador da produção do sofrimento e da indiferença moral dos seus executores. Esta é uma conclusão a que também chega Milgram através do seu já citado experimento: a separação ou a distância emocional da vítima concorre para a emergência do comportamento desumano e cruel. Dejours defende que o processo de banalização do mal, que para ele assume conotações diferentes de Arendt, também impregna o sistema liberal e contribui para seu desenvolvimento. Centrando sua análise no sofrimento produzido no universo do trabalho, ele sugere que, no caso do sistema atual, o fator desencadeante é a "manipulação política da ameaça de desemprego e da exclusão social" (2006, p. 119) e observa, como consequência do medo que tal ameaça provoca, uma evolução das reações sociais ante o sofrimento que culmina numa espécie de domesticação da indignação social. Tal estado de coisas acaba por tornar o sofrimento, próprio e alheio, progressivamente mais suportável, além de contribuir para o agravamento da situação do desemprego e de seus danos objetivos e subjetivos. Na avaliação de Dejours, a resposta adaptativa à adversidade seria um dos responsáveis pela inibição de reações coletivas em favor dos que sofrem.

Os medos e ansiedades constituem um dos importantes canais por onde a estrutura da sociedade é absorvida pela estrutura psicológica dos indivíduos. Os tipos, graus e intensidades dos medos e ansiedades variam em todas as sociedades e em fases históricas. São gerados e modificados pelas estruturas das relações sociais em determinados contextos históricos e requerem investigação acurada no sentido de se compreender o padrão de controle exercido sobre a conduta social e sobre os sentimentos em cada momento histórico. Exatamente, para se tentar explorar estas variadas configurações sociais ao longo da história, é que evocaremos o trabalho do sociólogo Norbert Elias. O autor propõe uma perspectiva psicossocial de estudo que enreda, de modo complexo, estruturas sociais e psicológicas na construção do que ele denomina de processo civilizador. Isso porque, para ele, "indivíduo" e "sociedade" são considerados aspectos diferentes dos mesmos seres humanos e se revestem, ambos, de um caráter processual. O viés explicativo adotado por Elias consiste em demonstrar empiricamente, como se deu, no curso da história ocidental, o controle das manifestações emocionais em direção à civilização.

A discussão de Dejours restringe-se ao mal padecido pelo sujeito no mundo do trabalho em um sistema liberal. Embora investigue os 
efeitos negativos do trabalho sobre a saúde mental dos trabalhadores, Dejours também considera o sofrimento do ponto de vista ético, quando se refere ao sofrimento infligido pelo sujeito aos outros ou quando considera sua mera cumplicidade na produção do sofrimento alheio. Estas situações podem, segundo o autor, afetar sua conduta moral particular ou afetar condutas coletivas, numa dimensão política mais ampla (2006, p. 36).

No que diz respeito a Elias, nós intencionamos compreender a interferência de certas configurações sociais ao longo da história ocidental para conhecer outros significados assumidos pelo sofrimento. Especulamos, também, se a atenuação das reações de indignação, prevista por Dejours e por outros autores, a partir de referenciais teóricos diversos, não integraria o próprio processo de desenvolvimento efetuado pela civilização ocidental. Particularmente, nos questionamos se a tolerância progressiva a certo tipo de sofrimento no mundo ocidental, atualmente, coincidiria com a continuidade do processo civilizador defendido por Elias. Talvez, uma nova configuração social, precipitada pelo medo progressivo causado pela ameaça de exclusão social permanente, concomitante ao avanço histórico do disciplinamento emocional propicie um grau extremo de controle das emoções, impelindo a formação de uma nova estrutura de personalidade - capaz de produzir um ego moderado, desapaixonado e distante emocionalmente do outro e do seu sofrimento. Neste caso, vislumbraríamos um mundo organizado em torno de relações sociais de indiferença e de falta de solidariedade, na qual, apáticos, reduziríamos o outro e seu sofrimento a meras categorias abstratas.

\section{Controle emocional e a continuidade do processo civilizador}

Em cada tempo e em cada sociedade sempre existiram limites definidores do que pode ou não pode ser tolerado, havendo uma compreensão tácita, de que certas regras sociais não devem ser infringidas e, de que, certos limites não podem ser ultrapassados. A expressão de alta dose de agressividade, seja ela física ou verbal, parece ser socialmente reprovada, de acordo com o nosso padrão moderno de manifestação emocional. Vários estudos identificam hoje um fenômeno amplo, no mundo ocidental, que expressa formas mais civilizadas e sutis de intolerância social (Vala, 1999). No entanto, nem sempre foi assim... Nem todo sofrimento era representado como sofrimento, nem todas as vítimas eram psicologicamente visíveis e, nem tampouco, a agressividade e a violência física eram encaradas como fontes de sofrimento.

Definitivamente, o sofrimento do outro não parece ser uma evidência, a menos que se conforme a determinado padrão histórico. Durante a 
Idade Média, por exemplo, havia grande prazer em atos de crueldade explícita e não havia, aparentemente, nenhuma tentativa de controle pessoal ou institucional na expressão da agressividade. Para o sociólogo Norbert Elias, o padrão de controle emocional é produzido, mantido ou modificado historicamente pelas estruturas de uma sociedade. Isto significa que, em determinado espaço histórico, as pessoas refletem, agem e interagem, estabelecendo suas gramáticas de dignidade e definindo critérios sobre o certo e o errado, sobre o que é normal e o que é anormal, sobre o que é tolerável e o que é intolerável... Assim, aquilo que em dado período é considerado razoável e, até mesmo, louvável, pode provocar repulsa e indignação em outro momento.

Em seu denso estudo O Processo Civilizador, escrito em 1939 em dois volumes, Norbert Elias (1939/1993) aborda a história do controle das emoções, demonstrando, através de vasto material empírico, desde o século XIII até o século $X X$, a evolução dos costumes na sociedade ocidental. Para ele, existe uma ordem social subjacente ao chamado processo civilizador, não propriamente racional nem irracional, que se desenvolve no curso da história de acordo com a seguinte dinâmica,

Planos e ações, impulsos emocionais e racionais de pessoas isoladas constantemente se entrelaçam de modo amistoso ou hostil. (...). Dessa interdependência de pessoas surge uma ordem sui generis, uma ordem mais irresistível e mais forte do que a vontade e a razão das pessoas isoladas que a compõem. É essa ordem social que determina o curso da mudança histórica (Elias, 1939/1993, vol. 2, p.194).

A esta estrutura de pessoas, reciprocamente dependentes, Elias define como Configuração, um conceito-chave na sua teoria, que expressa fielmente sua concepção de sociedade. A imagem da "dança de salão" ilustra, segundo ele próprio, um modelo adequado de configuração. A partir deste modelo, Elias pensa outras unidades sociais mais complexas como Estados, cidades, famílias, sistemas feudais, capitalistas e comunistas (1993, Vol. 1, p.250) e se propõe a apresentar, de forma concreta, como tais interdependências movimentaram a história, desde o sistema feudal até a formação do Estado Absolutista. Assim, a dança não pode ser concebida como abstração, uma vez que para ser dançada precisa dos indivíduos. Por outro lado, sem os indivíduos mutuamente orientados não há dança, embora esta não dependa de indivíduos específicos. A dança pode mudar, sendo dançada de forma mais rápida ou mais lenta. Sua análise a seguir evidencia a direção das referidas transformações históricas, 
Do período mais remoto da história do Ocidente até os nossos dias, as funções sociais, sob pressão da competição, tornaramse cada vez mais diferenciadas. Quanto mais diferenciadas elas se tornavam, mais crescia o número de funções e, assim, de pessoas das quais o indivíduo constantemente dependia em todas suas ações, desde as simples e comuns até as complexas e raras. À medida que mais pessoas sintonizavam sua conduta com a de outras, a teia de ações teria que se organizar de forma sempre mais rigorosa e precisa, a fim de que cada ação individual desempenhasse uma função social. O indivíduo era compelido a regular a conduta de maneira mais diferenciada, uniforme e estável (Elias, 1939/1993, vol.2, p.196).

De acordo com Elias, a diferenciação é apenas a primeira das muitas transformações que se sucedem no curso da civilização. No capítulo específico sobre mudanças na agressividade, no primeiro volume, Elias destaca que a expressão emocional explosiva passa a ser vista, progressivamente, como um comportamento primitivo, tornando-se objeto de controle de um poder central. Com a formação dos Estados Nacionais, e o consequente monopólio da força física, a violência fica restrita a autoridades legitimadas pelo poder central, não podendo mais ser exercida e estimulada socialmente. A manifestação de prazer em atos de crueldade passa a ser lentamente controlada a partir de sentimentos de medo e ansiedade gerados por práticas punitivas e, gradativamente, pela censura social.

Através da interdependência de grupos maiores de pessoas e da exclusão da violência física em seus contatos, é estabelecido um mecanismo social, no qual as limitações entre elas são transformadas em autolimitações. Estas autolimitações, que são função da visão retrospectiva e prospectiva instilada no indivíduo desde a infância, em conformidade com sua integração em extensas cadeias de ação, assumem em parte a forma de um autocontrole consciente e, em parte, a de um hábito automatizado" (Elias, 1939/1993, vol. 2, p.203).

É o que Elias (1994) denomina de segunda natureza. Os padrões de controle emocional no âmbito individual refletem, portanto, os padrões de controle das emoções produzidos socialmente. Esta é a sua tese, aprofundada na obra A sociedade dos Indivíduos. É exatamente por isso que sua investigação sobre o desenvolvimento da sociedade humana baseia-se numa perspectiva interdisciplinar na qual são articuladas, de forma indissociável, estruturas sociais, psíquicas e históricas. Através do conceito de configuração, o referido autor explicita sua peculiar concepção sobre sociedade e indivíduos, 
vistos como aspectos diferentes do ser humano, e revela o caráter processual das redes de interdependências formadas pelos indivíduos. Elias (1939/1993) adverte que a sobrevivência de toda sociedade depende de um controle efetivo dos comportamentos, de uma economia das pulsões e emoções dos indivíduos. O controle externo se desloca para dentro do indivíduo. A influência de Freud é clara na explicação dos mecanismos dos processos civilizatórios, como é o caso da formação do superego e sua relação na regulação do autocontrole. Com o monopólio da violência física, emergem espaços sociais pacificados nos quais os indivíduos se tornam menos vulneráveis a ação de ataques físicos diretos, contudo, como consequência, também o prazer é contido e sua satisfação passa a ser negociada e, muitas vezes, é substituída. Elias menciona a institucionalização de outros contextos sociais, como os jogos de caça e outras práticas esportivas, para os quais as emoções, controladas no cotidiano, são liberadas com certa segurança.

O autocontrole tem exercido grande importância na redução da violência, mas, em nome desta suposta segurança, a vida se tornou menos emocional. Freud declara mesmo que quanto mais avança a civilização, mais cresce a infelicidade. Esta é uma abordagem que, mais tarde, é aprofundada por Herbert Marcuse (1955/2013), no seu livro Eros e Civilização. Trata-se de uma questão controversa, objeto de grandes divergências teóricas. Para o psicólogo cognitivo Steven Pinker (2013), por exemplo, a teoria do processo civilizador é a única teoria sociológica capaz de explicar satisfatoriamente o declínio da violência na era moderna. Em seu trabalho, "Os Anjos Bons da Nossa Natureza: Por que a Violência diminuiu", Pinker advoga a causa da diminuição da violência, em grande parte, utilizando a argumentação teórica de Elias. Elias fundamentou sua previsão sobre 0 desenvolvimento da civilização na análise de livros de etiquetas e manuais de boas maneiras, considerando que não dispunha de estatísticas em sua época. Segundo Pinker, Elias não acertou apenas na previsão de tal declínio, como também acertou os períodos e lugares que, atualmente, não se beneficiaram desta queda. Para produzir seu livro, Pinker reúne um vasto número de dados empíricos mais recentes, baseados em gráficos e estatísticas de criminologistas, que demonstram a queda de homicídios na Europa, desde o período da Idade Média até os dias atuais.

Ao relacionar estudos de Psicologia e História, Pinker (2013) sugere que a redução da violência ocorreu em vários níveis, nas famílias, nas cidades, entre nações, etc. O seu livro consiste na árdua tarefa de convencer os descrentes leitores de que, talvez, atualmente, vivamos o período mais pacífico de nossa história. Sob certos pontos de vista, parece inconcebível considerar seriamente a imagem de mundo proposta por Elias, sobretudo, se observarmos os horrores perpetrados pela civilização nos últimos séculos. O próprio Elias, que 
testemunhou a ocorrência do Holocausto, sendo, também ele, alvo da perseguição nazista, teve certa dificuldade em sustentar, satisfatoriamente, sua perspectiva. Em defesa da tese de Elias e de sua própria tese, no entanto, Pinker esclarece que, mesmo durante o nazismo, o número de homicídios individuais decresceu, argumentando que a ordem de violência lá produzida apresenta natureza e causas totalmente diferentes e que, por isso, o holocausto e eventos da mesma categoria, não chegam a comprometer a razoabilidade da existência de um processo civilizador em curso. Em sua desafiante empresa, Pinker chama atenção para um aspecto interessante. Ele sugere que essa predisposição de nossa parte para duvidar do declínio da violência, ou seja, essa crença "ilusória" de que vivemos em um mundo progressivamente violento, perspectiva, segundo ele próprio, grandemente reforçada pela mídia, deriva exatamente das razões do decréscimo da própria violência. Em suas palavras, "o declínio do comportamento violento ocorreu paralelamente ao declínio de atitudes que toleram ou exaltam a violência" (2013, p. 20-21). Este parece ser um argumento fundamental em sua discussão, que indica a emergência progressiva de um estado de intolerância ao sofrimento e que difere, significativamente, do pensamento de Dejours. Considerando que a perspectiva de Pinker esteja correta, poderíamos considerar, por certo, que não se trata de uma intolerância a todo e qualquer sofrimento, mas daquele advindo da violência física. Seja como for, trata-se de uma perspectiva teórica bastante ousada que exige, no mínimo, uma análise mais cautelosa. A teoria do processo civilizador não é, exatamente, um consenso teórico na sociologia e tem sido alvo de críticas variadas (Bauman, 1998). O sociólogo polonês Zygmunt Bauman (1998) alerta que, à luz do Holocausto, a teoria do processo civilizador é parcial. Ele critica, particularmente, o fato de que tal teoria "desvia a atenção da permanência do potencial alternativo e destrutivo do processo civilizador e, efetivamente, silencia e marginaliza a crítica que insiste na duplicidade do moderno acordo social" (1998, p.48), sugerindo que o Holocausto é um produto legítimo do processo civilizador e não um fenômeno casual.

A exclusão da violência física do palco social produziu, de acordo com Elias (1939/1993), uma forma muito peculiar de segurança, capaz de gerar uma mudança ampla em todo o padrão de conduta social, que coincidiu com uma moderação das expressões emocionais. Nesse caso, talvez tenha apenas "evoluído" a intolerância a certas formas de manifestações afetivas mais exuberantes. Quando a violência física se torna objeto de um controle central, ainda segundo Elias, outras formas de violência que se encontravam a elas misturadas, passam a ser separadas, emergindo com mais clareza. É o caso, por exemplo, da violência econômica. A monopolização dos meios econômicos é uma das formas mais visíveis, nas sociedades 
pacificadas, nos dias de hoje, de indivíduos ou grupos exercerem domínio sobre outros. Há também outras formas de violências simbólicas que, exatamente por serem mais sutis, avançam neste contexto. São muitas as fontes de injustiças que produzem sofrimento nas sociedades contemporâneas. Às desigualdades materiais que causam exclusão social e que assumem uma dimensão mais visível, se somam as desigualdades simbólicas ocultadas nos discursos e ações sociais que privilegiam determinadas culturas à custa da desvalorização e falta de reconhecimento de outras. No novo cenário, o sofrimento alheio, muitas vezes, é tolerado porque deixa de ser visível ou, simplesmente, porque perde sua tonalidade intensa e torna-se silencioso, muito embora seja real. Mesmo a violência física, que não deixa de existir e atender certa função social na política, torna-se objeto de outro apertado controle social, sobretudo enquanto fenômeno espetacularizado. Neste campo, não é o Estado, mas a mídia que assume um papel fundamental, considerando que ela filtra, em grande medida, o que deve ser exibido publicamente, 0 que deve ser ocultado e o que deve indignar. As imagens das dores e sofrimentos alheios passam a ser expostas, com critérios, para regular o nível de envolvimento emocional adequado. Também a solidariedade, como última fronteira do controle social sobre as relações sociais, é institucionalizada, tendo em vista que são disponibilizados canais impessoais de ajuda através dos quais 0 telemarketing medeia o processo de doação, regulando 0 distanciamento social e o quinhão de responsabilidade social requerido. A eficiência do sistema midiático, no entanto, só é possível porque nossa organização social favorece a racionalização das manifestações emocionais. O disciplinamento da indignação social é, assim, estabelecido externamente, em nome da organização social, para, por fim, ser consolidado no nível psíquico. Esta regulação é consequência do próprio processo de interdependência de relações sociais em expansão e das configurações sociais que se consolidam. Este é o fato curioso na obra de Elias, através da dinâmica de interdependência social, causada por mudanças de comportamentos e mudanças na interação social, podem fazer emergir novas configurações sociais no processo civilizador.

Para Cas Wouters (2012), por exemplo, considerado o herdeiro intelectual de Elias, os processos disciplinadores começaram a caminhar no sentido de uma espécie de informalização dos costumes e emancipação das emoções. Fundamentado no mesmo tipo de referencial empírico de Elias, os livros de etiqueta, Wouters observou que a formalização dos costumes continuou até mais ou menos o século XIX, quando novas tendências despontaram. Para Wouters, que reafirma a análise de Elias, novas formas de regulação emocional apontam uma terceira natureza psíquica, que indica um resgate da primeira natureza, mais natural e descontraída, sem, contudo, perder 
os mecanismos rígidos de controle da segunda natureza. Trata-se de um "controle descontrolado" da vida emocional, um tipo de controle mais reflexivo, perpassado pela sensibilidade, que resulta dos mesmos processos de conexão entre integração social e integração psíquica. Dentre muitas, esta é uma leitura possível.

Considerando que a continuidade do processo civilizador não aponte uma única direção, indicamos outras possibilidades interpretativas. Particularmente, propomos aqui uma certa articulação com a tese desenvolvida pelo psiquiatra e psicanalista Christoph Dejours (2006), em sua obra, "A Banalização da Injustiça Social". Dejours defende a ideia de que, em um mundo injusto, a exposição permanente à violência simbólica, como a ameaça de exclusão social, na verdade, dilata a tolerância ao sofrimento, podendo culminar num processo de domesticação das reações emocionais de indignação social. Sugerimos que tal percurso pode coincidir com o processo de disciplinamento das emoções postulado por Elias, processo no qual a razão toma o lugar da emoção. É, não obstante, um caminho ainda não percorrido, que exige um estudo extenso e rigorosa fundamentação empírica. Por esta razão, propusemos tais reflexões em caráter apenas especulativo. São, portanto, reflexões que nos interpelam se a exposição ao sofrimento alheio em um mundo injusto pode nos levar, de fato, a uma estratégia de defesa permanente contra o estado de indignação social, desviando nossa ação da solidariedade e nossa atenção da injustiça e de suas causas.

\section{Conclusão}

A sociedade neoliberal tem produzido desigualdades sociais e um alto nível de injustiças materiais e simbólicas no mundo. O desemprego e mesmo o emprego, como sugere Dejours, têm sido apontados como fontes intensas de sofrimento. Analogamente, ao que ocorre no mundo do trabalho, outros contextos e fatores têm sido responsáveis por inumeráveis vicissitudes na vida hodierna. Este excesso de mazelas tem nos exposto a muitos infortúnios, desproporcionais ao alto grau de "civilização" atingido por nossa sociedade e desproporcionais, como diria Pinker, ao aumento de atitudes que toleram a violência. Além da produção de padrões de sofrimento peculiares, o mundo contemporâneo também aponta para duros retrocessos em nosso processo histórico, estes já previstos por Elias. Infelizmente, vimos assistindo, boquiabertos, ao reavivamento de formas "primitivas" de violência física, possivelmente produtos deste mesmo processo de indiferença social de que fala Dejours. Nesse sentido, talvez, a evolução da domesticação das reações emocionais tenha mais a dizer dos processos civilizatórios do que gostaríamos de acreditar... 
Na conclusão de sua obra seminal, em 1939, Elias sustentava que o processo civilizador não estava, em absoluto, terminado. Falava de um mundo que ainda não era o nosso, embora já antevisse muitos dos nossos problemas atuais. Para ele, assim como para nós, a estrutura social, os padrões de conduta, os medos, as tensões e os conflitos não são definitivos, antes, resultam do contínuo e dinâmico nível de entrelaçamento social. Em face disto, sua recomendação para conhecermos melhor tais processos, delineados na história, e para interferirmos, com mais consciência em seu curso, permanece válida.

\section{Referências}

Bauman, Z. (1998). Modernidade e Holocausto. Rio de Janeiro: Jorge Zahar Ed.

Bock, A. M. B. (1999). As aventuras do Barão de Münchhausen na psicologia. São Paulo: EDUC: Cortez Editora.

Dejours, C. (2006). A banalização da injustiça social. Rio de Janeiro: Editora FGV.

Elias, N. (1939/1993). O processo civilizador. (Vols. 1-2). Rio de J aneiro: J orge Zahar Ed.

Elias, N. (1994). A sociedade dos indivíduos. Rio de Janeiro: Jorge Zahar Ed.

Marcuse, H. (1955/2013). Eros e civilização: uma interpretação filosófica do pensamento de Freud. Rio de Janeiro: LTC.

Milgram, S. (1974). Obedience to authority. New York: Haper and Row.

Moscovici, S. (2003). Representações Sociais: Investigações em psicologia social. Petrópolis, RJ : Vozes.

Packer, D. J. Identifying Systematic Disobedience in Milgram's Obedience Experiments: A Meta-Analytic Review (2008). Perspspectives on Psychological Science, 3, 301-304.

Pinker, S. (2013). Os anjos bons da nossa natureza: Por que a violência diminuiu. São Paulo: Companhia das Letras.

Vala, J. (1999). Novos racismos: Perspectivas comparativas. Oeiras: Celta Editora.

Wouters, C. (2012). Como continuaram os processos civilizadores: rumo a uma informalização dos comportamentos e a uma personalidade de terceira natureza. Revista Sociedade e Estado, 27(3), 546-570. 


\section{Endereço para correspondência}

\section{Sandra Leal de Melo Dahia}

Universidade Federal da Paraíba

Centro de Ciências Humanas, Letras e Artes

Campus I, Cidade Universitária, CEP 58059-900, João Pessoa - PB, Brasil

Endereço eletrônico: sandradahia@yahoo.com.br

Recebido em: 05/04/2016

Reformulado em: 13/04/2017

Aceito em: 04/04/2017

\section{Notas}

* Possui graduação em Psicologia (UFPB), mestrado em Ciências Sociais (UFPB) e Doutorado em Sociologia (UFPB). É docente na Universidade Federal da Paraíba.

Este artigo de revista Estudos e Pesquisas em Psicologia é licenciado sob uma Licença Creative Commons Atribuição-Não Comercial 3.0 Não Adaptada. 